\title{
Klinik örneklerden izole edilen Acinetobacter baumannii suşlarının in-vitro duyarlılık durumları
}

\section{In-vitro susceptibility of Acinetobacter baumannii strains isolated from clinical specimens}

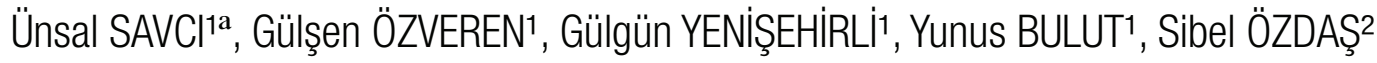

1 Gaziosmanpaşa Üniversitesi Tıp Fakültesi, Mikrobiyoloji ve Klinik Mikrobiyoloji Anabilim Dalı, Tokat, ${ }^{2}$ Hacettepe Üniversitesi, Fen Fakültesi, Biyoloji Bölümü, Ankara, Türkiye - TÜRKiYE

\begin{abstract}
ÖZET
Amaç: Acinetobacter baumannii pek çok antibiyotiğe karşı direnç gösterdiğinden ve yeni antibiyotiklere karşı hızla direnç geliştirebilmesinden ötürü tedavide zorluk çıkarmaktadır. Hastanede ve özellikle yoğun bakım ünitelerinde tedavisi güçlük gösteren pnömoni, ventilatörle ilişkili pnömoni, üriner infeksiyon, kateter infeksiyonları, kan dolaşım yolu infeksiyonları ve menenjit gibi infeksiyonlara yol açabilir. Bu çalışmada hastanemizde çeşitli klinik örneklerden izole edilen 170 adet Acinetobacter baumannii suşunun antibiyotik duyarlılıklarının belirlenmesi amaçlanmıştır.

Gereç ve Yöntemler: Çalışmaya, Ocak 2005-Mayıs 2012 tarihleri arasında mikrobiyoloji laboratuvarına gönderilen klinik örneklerden izole edilen 170 Acinetobacter baumannii suşu dahil edilmiştir. İzolatların amikasin, ampisilin-sülbaktam, sefepim, sefotaksim, seftazidim, solistin, gentamisin, imipenem, meropenem, tetrasiklin, trimetoprim-sulfametaksazol, tobramisin, piperasilin-tazobaktam, siprofloksasin ve tigesiklin antibiyotiklerinin Phoenix 100 (Becton Dickinson, USA) otomatize identifikasyon cihazı ile mikrodilüsyon yöntemi ve Kirby-Bauer disk difüzyon yöntemi ile duyarllıkları belirlenmiştir.

Bulgular: Acinetobacter baumannii suşları en sık (\%39) ile solunum yolu örneklerinden, ikinci sırada kan örneklerinden (\%23), yara (\%21), idrar (\%14), kateter (\%1) ve beyin omurilik sııısından (\%1) izole edilmiş̧ir. A. baumannii suşlarının \% 42'si yoğun bakımlar, \%16'sı göğüs hastalıkları servisi, $\% 7$ ortopedi servisi, $\% 7$ genel cerrahi servisi ve $\% 14$ diğer klinik servislerden ve $\% 12$ polikliniklerden izole edilmiştir.

Bu suşlara direnç oranları; kolistin $\% 3$, tobramisin $\% 8$, tigesiklin $\% 15$, amikasin $\% 65$, sulbaktam-ampisilin- $\% 95$, sefepim $\% 93$, sefotaksim $\% 97$, seftazidim $\% 93$, gentamisin $\% 90$, imipenem $\% 66$, meropenem $\% 65$, tetrasiklin $\% 62$, trimetoprim-sulfametaksazol $\% 66$, piperasilin-tazobaktam $\% 93$ ve siprofloksasin \%92 olarak saptanmıştır.

İmipenem için 2009 ylına kadar direnç oranı \%0 iken, 2011 ylında direnç oranı \%88,57’e yükselmiştir. Kolistin için 2012 ylında ilk dirençli suş saptanmıştır.

Sonuç: 2005 ylından 2012 ylına kadar yedi yillık süreçte direnç oranlarının hızla artı̆ğ görülmüşsür. Antimikrobiyal ajanlara karşı direnç oranlarının yüksek olmasının hastanelerde bu antimikrobiyallerin sık kullanıımasından kaynaklandığı düşünülmektedir. Acinetobacter suşlarına karşı en etkili antibiyotiğin kolistin olduğu görülmüştür.
\end{abstract}

Anahtar Kelimeler: Acinetobacter baumannii, antimikrobiyal duyarllık, çoklu ilaç direnci 


\begin{abstract}
Aim: Management of Acinetobacter baumannii infection is usually difficult due to increase in multi-drug resistant Acinetobacter baumannii srains and rapid development of resistance to new antimicrobial drugs. It may cause nosocomial infections such as pneumonia, ventilator-associated pneumonia, urinary tract infections, blood stream infections, meningitis especially in intensive care units. The aim of this study was to evaluate the antimicrobial susceptibilities of $170 \mathrm{~A}$. baumanii strains isolated from clinical specimens in our hospital.
\end{abstract}

Material and Methods: A total of $170 \mathrm{~A}$. baumanii strains isolated from clinical specimens in our microbiology laboratory during February 2005May 2012 were included the study. A. baumanii isolates were identified by using BD Phoenix 100 (Becton Dickinson, USA) Amikasin, sulbactamampicillin, cefepime, cefotaxime, ceftazidime, colistin, gentamicin, imipenem, meropenem, tetracycline, trimethoprim-sulfamethoxazole, tobramycin, piperacillin-tazobactam, ciprofloxacin and tigecycline susceptibilities of $A$. baumanii isolates were determined by using BD Phoenix 100 (Becton Dickinson, USA) automated system and Kirby-Bauer disk diffusion method.

Results: The source of $A$. baumanii isolates was predominantly respiratory tract, yielding $67(39 \%)$, while 40 (23\%) isolates were from blood, 36 (21\%) from wound, 24 (14\%) from urine, 1 (0.6 \%) from catheter, $1(0.6 \%)$ from cerebrospinal fluid.

Forty two percent of $A$. baumanii isolates were isolated from ICU, sixteen percent from chest disease service, seven percent from orthopedic service, seven percent from general surgery service, fourteen percent from other clinic services and twelve percent from outpatient clinics.

The resistance rates of $A$. baumanii to amikasin, sulbactam-ampicillin, cefepime, cefotaxime, ceftazidime, colistin, gentamicin, tobramycin, imipenem, meropenem, tetracycline, trimethoprim-sulfamethoxazole, piperacillin-tazobactam, ciprofloxacin and tigecycline were found $65 \%$, $95 \%, 93 \%, 97 \%, 93 \%, 3 \%, 90 \%, 8 \%, 66 \%, 65 \%, 62 \%, 66 \%, 93 \%, 92 \%$, and $15 \%$ respectively.

The imipenem resistance rate increased significantly from $0 \%$ to $88.57 \%$ in a study period. One of the $A$. baumanii isolate was found to be colistin resistant in 2012.

Conclusion: In this study colistin was found to be most effective antimicrobial driug agains $A$. baumanii isolates. We also observed that the resistance rates of $A$. baumanii isolates to tested antimicrobial drugs are progressively increased in 7 years period. It is well known that wide spread use of antimicrobial drugs promotes the spread of antimicrobial resistance. Overuse and misuse of antimicrobial drugs must be taken under control immediately.

Key Words: Acinetobacter baumannii, antimicrobial susceptibility, multi-drug resistance

\section{Giriş}

A. baumanii nonfermentatif, gram-negatif, son ylllarda önemi giderek artan, hastane ortamında yaygın olarak bulunan, pek çok ilaca karşı direnç geliştirmiş bir bakteridir. A.baumannii pek çok antibiyotiğe karşı direnç gösterdiğinden ve yeni antibiyotiklere karşı hızla direnç geliştirebilmesinden ötürü tedavide zorluk çıkarmaktadır. Hastanede ve özellikle yoğun bakım ünitelerinde tedavisi güçlük gösteren pnömoni, ventilatörle ilişkili pnömoni, üriner infeksiyon, kateter infeksiyonları, kan dolaşım yolu infeksiyonları ve menenjitlere yol açabilir [1].

A. baumanii infeksiyonları sıklıkla yoğun bakım ünitelerinde gözlenmektedir. Kullanılan mekanik aletlerin yüzeyine kolonize olmaları, geniş spektrumlu antibiyotiklerin kullanılması, hastalar ve hastane personelinde kolonize olmaları, cansız ve kuru yüzeylerde uzun süre canlı kalabilmeleri $A$. baumanii infeksiyonlarının yoğun bakım ünitelerinde sık görülme nedenlerini açıklamaktadır [2]. Nozokomiyal $A$. baumanii infeksiyonlarına bağlı mortalite oranları oldukça yüksek olup, bakteriyemide \%25-34, nozokomiyal pnömonide $\% 40-80$ olarak bildirilmektedir $[3,4]$.

Hastanelerde geniş spektrumlu antibiyo-tiklerin yaygın kullanımına bağlı olarak $A$. baumanii türleri nozokomiyal infeksiyonlarının en sık saptanan etkenlerinden biri haline gelmiştir. A. baumanii türleri hastane infeksiyonlarının \%3-20'sinden sorumludur [5]. Klinik örneklerden en çok izole edilen Acinetobacter türü A. baumanii' dir [6]. A. baumanii infeksiyonlarındaki en önemli sorun, bakterinin karbapenemler de dahil bir çok antibiyotiğe dirençli olmasıdır $[7,8,9]$. Bu durum tedavide yeni seçenek ilaçların araş- tırımasını gerektirmiştir [10]. Bu çalışmada çeşitli klinik örneklerinden izole edilen $A$. baumanii suşları-nın antibiyotiklere duyarlııkları ve yıllara göre direnç gelişimlerinin araştırıması amaçlanmıştı.

\section{Gereç ve Yöntemler}

Çalışmamızda 2007-2012 yılları arasında yoğun bakım ünitesi, yataklı servisler ve poliklinik hastalarından izole edilen $170 \mathrm{~A}$. baumanii suşları retrospektif olarak değerlendirilmiş̧tir. Örnekler $\% 5$ koyun kanlı agar, insan kanlı agar, eosine methylene blue (EMB) besiyeri ve çukulatamsı agar besiyerine ekildi. Tür tanımlama işlemleri, gram boyama, oksidaz testi ve BD Phoenix System (Beckton Dickinson, ABD) kullanılarak üreticinin önerilerine göre yapıldı.

Izole edilen bakterilerin identi-fikasyonu konvansiyonel yöntemler ve BD Phoenix System (Beckton Dickinson, ABD) tanımlama kitleri ile izolatların 13 farklı antimikrobiyal ilaca duyarlıkları araştııımış, antibiyotik duyar $\neg|||| k$ testleri BD Phoenix System (Beckton Dickinson, ABD) mikrodilisyon yöntemi ile yapılmıs, BD Phoenix System (Beckton Dickinson, ABD) panelleri içerisinde olmayan Tigesiklin ve Tobramisin antibiyotik duyarllık testleri Kirby-Bauer disk difüzyon yöntemi ile yapıımıştır. Tobramisin için antibiyotik duyarllık testi Clinical and Laboratory Standards Institute (CLSI) standartlarına göre Kirby-Bauer disk difüzyon yöntemi kullanıımış $\neg$ tı. Tigesiklin için inhibisyon zon çapları $\leq 12 \mathrm{~mm}$ ise dirençli, $\geq 16 \mathrm{~mm}$ ise duyarlı kabul edilmiştir [11]. Tobramisin için zon çapları $\leq 12 \mathrm{~mm}$ ise dirençli, $\geq 15 \mathrm{~mm}$ ise duyarlı kabul edilmiş̧tir [12]. 
Çalışmada Escherichia coli ATCC 25922 suşu kalite kontrolü amacıyla kullanılmıştır [13]. Orta duyarlı suşlar dirençli olarak kabul edilmiştir. Çalışmamızda elde edilen verilerin istatistik analizi için "SPSS for 16.0" (Statistical Package for Social Sciences; version 16.0, SSPS Inc, Chicago, IL, USA) programı kullanıldı. Sürekli değişkenler medyan, kategorik değişkenler ise sayı ve yüzde ile gösterildi.

\section{Bulgular}

Kültürlerinde $A$. baumanii üreyen 170 hasta değerlendirildiğinde; ortalama yaş 51.27, standart sapma (SD), \pm 16.38 idi. 170 hastanın 109'u (\%64) erkek, 61'i (\%36) kadındı.71 hasta (\%42) yoğun bakım, 79 hasta (\%46) yataklı servisler ve $20(\% 12)$ hasta ise poliklinik hastasıydı. Suşların izole edildikleri servislere göre dağılımı Tablo l'de verilmişsir. Yoğun bakım üniteleri hastane infeksiyonlarının en sık görüldüğü birimlerdir ve buna paralel olarak $A$. baumanii infeksiyonları da en sık yoğun bakım ünitelerinde görülmektedir [14]. Çalışmamızda $A$. baumanii infeksiyonları en sık yoğun bakımlardan izole edilmiştir.

Tablo 1: Acinetobacter baumannii suşlarının izole edildikleri birimlere göre dağıımı

\begin{tabular}{|l|c|c|}
\hline Birim & $\mathbf{n}$ & $\%$ \\
\hline Yoğun Bakımlar & 71 & 42 \\
\hline Göğüs Servisi & 27 & 16 \\
\hline Ortopedi Servisi & 12 & 7 \\
\hline Genel Cerrahi Servisi & 11 & 7 \\
\hline Beyin Cerrahi Servisi & 7 & 3 \\
\hline Dâhiliye Servisi & 6 & 3 \\
\hline Nöroloji Servisi & 6 & 3 \\
\hline Kardiyoloji Servisi & 5 & 3 \\
\hline Üroloji Polikliniği & 5 & 3 \\
\hline Pediatri Servisi & 4 & 3 \\
\hline Göğüs Polikliniği & 4 & 3 \\
\hline Kadın Doğum polikliniği & 2 & 1 \\
\hline Üroloji Servisi & 1 & 1 \\
\hline Diğer & 9 & 5 \\
\hline Toplam & 170 & $\% 100$ \\
\hline
\end{tabular}

$\mathrm{n}$ : İole edilen suş sayısı

\%: İole edilen suş oranı

Suşlarının izole edildikleri klinik örneklere göre dağlımı Tablo 2'de verilmiştir.

Tablo 2: Acinetobacter baumannii şuşlarının klinik örneklere göre dağıımı

\begin{tabular}{|l|c|c|}
\hline Örnek & $\mathbf{n}$ & $\mathbf{\%}$ \\
\hline Solunum yolu örnekleri & 67 & 39 \\
\hline Kan & 40 & 23 \\
\hline Yara & 36 & 21 \\
\hline İdrar & 24 & 14 \\
\hline Kateter & 1 & 0,6 \\
\hline Beyin Omurilik SIvISI & 1 & 0,6 \\
\hline Vaginal sürüntü & 1 & 0,6 \\
\hline Toplam & 170 & $\% 100$ \\
\hline
\end{tabular}

En sık izole edilen klinik örnek solunum yolu örnekleriydi. Solunum yolu örneklerini trakeal aspirat, balgam ve bronj lavajı oluşturmaktaydı. İzole edilme sıklıklarına göre solunum yolu örneklerini sırasılyla kan ve yara örnekleri izlemekteydi.

A. baumanii izolatlarının yıllara göre antibiyotik direnç yüzdeleri, direnç değişimleri Tablo 3'de verilmiştir.

Tablo 3: Acinetobacter baumanni suşlarında yıllara göre antibiyotiklere direnç oranları [n (\%)]

\begin{tabular}{|c|c|c|c|c|c|c|}
\hline Antibiyotikler & 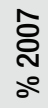 & 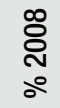 & $\begin{array}{l}\text { 오 } \\
\text { ঠீ }\end{array}$ & $\begin{array}{l}\text { 웅 } \\
\text { N } \\
\text { 웅 }\end{array}$ & $\begin{array}{l}\bar{N} \\
\text { స్ } \\
\text { 。 }\end{array}$ & $\begin{array}{l}\text { N } \\
\text { N } \\
\text { ஃ̊ }\end{array}$ \\
\hline Amikasin & 52 & 58 & 92 & 54 & 64 & 71 \\
\hline Sefepim & 87 & 75 & 96 & 92 & 92 & 97 \\
\hline Sefotaksim & 96 & 100 & 100 & 95 & 98 & 100 \\
\hline Seftazidim & 84 & 72 & 100 & 90 & 94 & 96 \\
\hline Kolistin & 0 & 0 & 0 & 0 & 0 & 0,6 \\
\hline Gentamisin & 63 & 72 & 95 & 90 & 94 & 95 \\
\hline İmipenem & 0 & 0 & 19 & 36 & 88 & 96 \\
\hline Meropenem & 0 & 9 & 24 & 36 & 88 & 96 \\
\hline Tetrasiklin & 36 & 17 & 22 & 41 & 13 & 90 \\
\hline Trimetoprim-Sufametoksazol & 16 & 36 & 21 & 44 & 92 & 80 \\
\hline Piperasilin Tazobaktam & 79 & 100 & 100 & 90 & 94 & 99 \\
\hline Siprofloksasin & 79 & 72 & 100 & 90 & 94 & 95 \\
\hline Tigesiklin & 7 & 9 & 11 & 13 & 12 & 16 \\
\hline
\end{tabular}

A. baumanii suşlarında; karbapenemlerden imipenem ve meropenem için 2007 yllında hiç dirençli suşa rastlanmazken, direnç yıllar içerisinde artmış ve 2012 yılında diren oranı \%92 olmuştur. Sefalosporinlere direnç oranı belirtilen tarihlerde hep yüksek olmuştur.

Kolistine ilk direçli suş 2012 ylında saptanmıştır. Tigesiklin için direnç oranları 2007 yılında \%7'den 2012 yılında \%16'ya yükselmiştir. Trimetoprim-Sufametoksazole ilk yıllarda direnç oranı düşük iken \%80'e kadar çıkmıştır.

Tablo 4: Acinetobacter baumanni suşlarının birimlere göre antibiyotik direnç oranları

\begin{tabular}{|r|c|c|c|}
\hline Antibiyotikler & YB\% & Pol\% & Ser\% \\
\hline Amikasin & 62 & 59 & 63 \\
\hline Sefepim & 100 & 64 & 87 \\
\hline Sefotaksim & 100 & 93 & 96 \\
\hline Seftazidim & 100 & 74 & 87 \\
\hline Kolistin & 0,6 & 0 & 0 \\
\hline Gentamisin & 98 & 63 & 87 \\
\hline İmipenem & 76 & 40 & 62 \\
\hline Meropenem & 76 & 37 & 64 \\
\hline Tetrasiklin & 62 & 52 & 63 \\
\hline Trimetoprim-Sufametoksazol & 76 & 47 & 70 \\
\hline Piperasilin Tazobaktam & 100 & 68 & 87 \\
\hline Siprofloksasin & 100 & 74 & 87 \\
\hline Tigesiklin & 14 & 9 & 10 \\
\hline
\end{tabular}

YB\%:Yoğun bakım direnç oran Pol\%:Poliklinikler direnç oranı Ser\%:Servisler direnç oranı 
A. baumanii izolatlarının birim bazında antibiyotik direnç oranları Tablo 4'de gösterilmiştir. Amikasin ve tetrasiklin antibiyotikleri hariç diğer antibiyotiklere en yüksek direnç oranları yoğun bakımlarda görülmüştür. Bunu yatakı servisler ve poliklinikler izlemiş̧tir. Çalışmamızda en etkili antibiyotik olan kolistin direnci yoğun bakımda saptanmıştır.

\section{Tartışma}

Nozokomiyal enfeksiyonlar yüksek mortalite, morbidite, hastane de kalış sürelerinin uzaması ve yüksek masraflar nedeni ile önemli bir sağllk sorunudur. Nozokomiyal infeksiyonların neden olduğu ek mortalite oranlarının ise \%4-33 arasında değiştiği saptanmışıı [15]. A. baumanii suşlarında beta-laktam antibiyotiklere karşı direnç beta-laktamaz üretimi, beta-laktam antibiyotiğin dış membran porinlerinden girişinin azalması ve penisilin bağlayan proteinlerde değişiklik sonucu meydana gelmektedir [16]. 1980'li yıllarda ciddi nefrotoksisiteleri nedeniyle parenteral kullanımı terk edilerek, daha az toksik etkileri olan yeni grup antibiyotikler polimiksinlerin yerini almıştır. Son yıllarda izlenen çoklu ilaç direnci bulunan gramnegatif bakteriler (özellikle Pseudomonas spp. ve Acinetobacter spp.) ile oluşan infeksiyonların sıklığında artış ve tedavilerinde yaşanan sorunlar polimiksinleri tekrar gündeme getirmiş̧tir.

Ancak günümüzde kolistin ile ilgili klinik deneyim oldukça sınırlı olup ciddi yan etkilerinden dolayı klinik kullanımı çok yaygın değildir [17]. Villalon ve ark. [18] İspanyada çeşitli hastanelerden almış oldukları 729 A. baumanii suşunda ve Kofteridis ve ark. [19] da Yunanistan'da 66 A. baumanii suşunda kolistin direncine rastlamadıklarını bildirmişlerdir. Bogiel ve ark. [20] ise Polonya'da yaptıkları çalışmada $A$. baumanii suşlarında kolistin direncini $\% 1,5$ olarak bildirmişlerdir.

Çalışmamızda 2007 ylından 2012 ylına kadar kolistin direncine rastlanmamış, 2012 ylında ilk kolistin direnci görülmüştür. Bu hasta yoğun bakımda yatmakta ve beyin omurilik sıvısında $A$. baumanii izole edilmiştir. Uzun süre kolistin tedavisi uygulanmıştr.

Özellikle yoğun bakım ünitelerinde yatan hastalardan, malignitelilerden, immün sistemi baskılanmış hastalardan, yanık hastalarından ve yeni doğanlardan izole edilen $A$. baumanii suşlarına karşı in-vitro direnç oldukça yüksek oranlarda görülmektedir [21].

A. baumanii enfeksiyonlarının tedavisinde yeni secenek ilaçların başında tigesiklin gelmektedir. Bu antibiyotiğin, coğul ilaç direnci olan A. baumanii suşlarında etkili olduğu gözlenmisştir. Yeni bir antibiyotik olan tigesiklin, tetrasiklin grubundan minosiklin türevi bir glisilsiklindir. Çoğu gram pozitif ve gram-negatif, aerop ve anaerop bakterileren karşı güçlü bir in vitro aktiviteye sahiptir [22].

Tigesiklin, Türkiye'de 2008 ylında klinik kullanıma girmiş, tetrasikline benzerlik gösteren geniş spektrumlu bir antibiyotik olup, 30S ribosomal alt birime bağlanarak protein sentezini engellemektedir [23].

Pachon-Ibanez ve ark. imipeneme dirençli $A$. baumanii suşlarından \%92'sini tigesikline duyarlı olarak bildirmişlerdir [10]. Bizim çalışmamızda 2007 yilında \%7 olan direnç oranı 2012 yilında \%16 olarak bulunmuştur.

Bunları \%49,57 direnç oranı ile karbapenemler, \%57,85 ile tetrasiklin,
\%57,99 ile trimetoprim-sulfametoksazol ve \%66,27 ile amikasin izlemiştir. Diğer antibiyotiklere direnç oranları \%88,46 ile \%97,05 arasında değişim göstermiştir (Tablo 3).

Karbapenem direnci beta-laktamazlarla enzimatik inaktivasyon, dış membran proteinlerinde kayıp, penisilin bağlayan proteinlerde değişme ve özgül ilaç efluks pompaları ile ortaya çıkar. Pek çok karbapenem dirençli A. baumanii sușları OXA-laktamazlara sahiptir [24].

Acinetobacter türlerinde karbapenemlere karşı hızla direnç gelişmesi kaygı vericidir ve gelecekte alternatif ilaç kalmayacağı korkusunu uyandırmaktadır. Guriz ve ark.nın [25] 1999 yılında yaptıkları çalışmada, hastane enfeksiyonu etkeni olan 65 Acinetobacter spp. izolatnda imipeneme dirence rastlanmamışlardır. Ayrıca 2008-2010 yılları arasında yapılan üç farklı çalışmada imipenem direnç oranları sırasıyla $\% 70, \% 83$ ve \%84 olarak tespit edilmiştir $[26,27]$.

Bizim izolatlarımızda da imipeneme direnç oranı 2007 ve 2008 yılı için direnç oranı \%0 iken, hızla artarak 2009 ylında \%19, 2010 da \%36, $2011 \% 88$ ve 2012 ylında \%96 olarak bulunmuştur. Meropenem direnç oranları da imipeneme benzer oranda hızla artmıştır. Özellikle karbapenemlere direncin anlamlı bir şekilde hızlı artışı ürkütücüdür.

Acnetobacter türlerinde aminoglikozitlere aminoglikozit modifiye edici enzimler (asetilaz, adenilaz, fosfotransferaz), hedef ribozomal proteinlerde bozulma, aminoglikozidlerin bakteri içerisine girişinin engellenmesi ve efluks pompası ile direnç gelişmektedir [28].

Özellikle çoklu ilaca dirençli Acinetobacter türlerinde tedavi seçeneği olarak tobramisin ve amikasin gibi aminoglikozitler, başka bir aktif antimikrobiyal ajanla kombine olarak kullanılmaktadır [29].

İspanya'da yapılan bir çalışmada altı yllık bir periyot içinde amikasin direncinin \%21'den \%83,7'ye yükseldiği bildirilmiştir [30]. Farkı araştırclar amikasin direncini \%39-94,5 gentamisin direncini ise \% 37-100 arasındaki oranlarda bildirmişlerdir [21,30-37].

Çalısmamızda 2007 ylında \%52 iken amikasin direnci 2009 yilında \%92 gibi yüksek bir orana çıkmıştır. 2010 ylında amikasin direnci \%54'e düşmüştür. Bu oranın azalması yüksek in vitro amikasin direncinden dolayı kullanımının azalmasına bağlanabilir. 2011 ve 2012 yıllarındaki artışla direnç \%71'e çıkmıştır. Çalıșmamızda gentamisin direnci 2007 ylında \%63'ten 2012 yllında \%95'e çıkmıştı.

Balcı ve ark. tarafindan seftazidim, seftriakson, sefotaksim, sefepim için direnç oranları sırasıyla, $\% 99, \% 97, \% 96$ ve $\% 95$ olarak bildirilmiștir [21].

Çalışmamızda seftazidim, sefotaksim, sefepim için direnç oranları sırasıyla \%87, \%96 ve \%84 olarak oldukça yüksek direnç oranları saptanmıştır. Sefalosporinlere bu kadar yüksek düzeyde direnç olması, toplumda ve hastanede çok yaygın kullanımlarına bağlı olabilir.

Tetrasiklin dirençi ilaç efluks pompası veya ribozomal koruyucu sistemle ortaya çıkmaktadır. Kurtoğlu ve ark. çalışmalarında tetrasiklin direncini \%72 olarak bildirmişlerdir [38].

Çalışmamızda Tetrasiklin direnci 2007 ylında \%36 iken 2011 yllına kadar dalgalı bir seyir izlemiş ve 2011 ylında \%13'e kadar düşmüştür. Fakat 2012 yılında çok hızlı bir artışla \%90'a çıkmışıı. 
DNA giraz ve topoizomeraz 4'de, kromozomal ilaç giriş ve ilaç pompa sistemlerinde mutasyon sonucu florokinolonlara direnç gelişmektedir. Trimetoprim sulfametoksazol direnci en sık dihidrofolat redüktaz mutasyonu ile ortaya çıkar [39]. Çalışmamızda siprofloksasin için altı yıllık sürede direnç oranları oldukça yüksek olarak \%87, trimetoprim sulfametaksazol için 2007 yılında \%16 olan direnç anlamlı bir şekilde artarak 2012 yılında \%80'e çıkmıştır.

Kolistin ve tigesiklin'e direnç oranları sırasıyla \%4 ve \%11 olarak saptanmıştır. Suşların hepsi bir arada değerlendirildiğinde bu antibiyotiklerin yüksek etkili olduğu düşünülmektedir.

Çalışmamızda $A$. baumanii suşlarına en etkili antibiyotiklerin kolistin ve tigesiklin olduğu görülmektedir. Fakat bu antibiyotiklere karşı gelişen direnç önümüzdeki yıllar için korkutucudur. Bu nedenle yeni antibiyotiklerin geliştirilmesi gerekmektedir. Çoğul antibiyotik direncine sahip olan bu mikroorganizmanın hastane ortamında sınırlandırıması için enfeksiyon kontrol ve önlemlerinin azami derecede uygulanması ve in vitro direnç profillerinin takip edilmesi, tedavinin in vitro duyarılık ile korele olması faydalı olacaktır.

\section{Kaynaklar}

1. Bergogne-Berezin E, Towner KJ: Acinetobacter spp. as nosocomial pathogens: microbiological, clinical, and epidemiological features. Clin Microbiol Rev 1996;9:148-65.

2. Villages MV, Hartstein Al. Acinetobacter outbreaks 1997-2000. Infect Control Hosp Epidemiol 2003;24:284-95

3. Fagon JY, Chastre J, Hance AJ, et al Nosocomial pneumonia in ventilated patients: a cohort study evaluating attributable mortality andhospital stay. Am J Med 1993;94:281-8.

4. Garnacho-Montero J, Ortiz-Leyba C, Jimenez- Jimenez FJ, et al Treatment of multidrug-resistant Acinetobacter baumannii ventilatorassociatedpneumonia (VAP) with intravenous colistin: a comparison with imipenem-susceptible VAP. Clin Infect Dis 2003;36:1111-8.

5. Gündeş $\mathrm{S}$, Vahaboğlu H: Acinetobacter türleri ve Acinetobacter ile gelişen enfeksiyonlar. Enfeksiyon Hastalıkları Serisi 2003;6:147-56.

6. Winn WJ, Allen S, Janda W et al The nonfermentative Gram-negative bacilli, "Winn WJ, Allen S, Janda W, Koneman E, Procop G, Schreckenberger P, Woods G (eds): Koneman's Color Atlas and Textbook of Diagnostic Microbiology, Sixth ed." kitabında s.303-91, Lippincott Williams and Wilkins, Philadelphia (2006).

7. Cisneros JM, Reyes MJ, Pachon J, et al Bacteremia due to Acinetobacter baumannii: epidemiology, clinical findings, and prognostic features. Clin Infect Dis 1996;22:1026-32.

8. Fagon JY, Chastre J, Hance AJ, et al Nosocomial pneumonia in ventilated patients: a cohort study evaluating attributable mortality and hospital stay. Am J Med 1993;94:281-8.

9. Bou G, Cervero G, Dominguez MA, Quereda C, Martinez Beltran J. Characterization of nosocomial outbreak caused by a multiresistant Acinetobacter baumannii strain with a carbapenem-hydrolyzing enzyme: high-level carbapenem resistance. J Clin Microbiol 2000;38:3299-305.
10. Pachon Ibanez ME, Jimenez Mejias ME, Pichardo C, Llanos AC, Pachon J. Activity of tigecyline (GAR-936) against Acinetobacter baumannii strains, including those resistant to imipenem. Antimicrob Agent Chemother 2004;48:4479-81

11. Jones RN, Ferraro MJ, Reller LB, Schreckenberger PC, Swenson JM, Sader HS: Multicenter studies of tigecycline disk diffusion susceptibility results for Acinetobacter spp. J Clin Microb 2007;45:227-30.

12. Clinical and Laboratory Standards Institute (CLSI) standards for antimicrobial susceptibility testing, document M02-A10 and M07-A8.

13. Clinical and Laboratory Standards Institute: Performance Standards for Antimicrobial Susceptibility Testing, Seventeenth informational supplement M100-S15, Clinical and Laboratory Standards Institute, Wayne, Penn (2007).

14. Bergogne-Berezin E, Towner KJ: Acinetobacter spp. as nosocomial pathogens: microbiological, clinical, and epidemiological features. Clin Microbiol Rev 1996;9:148-65.

15. Vançelik S, Özden K, Özkurt Z, Altoparlak Ü, Aktaş E, Savcı AB: Atatürk Üniversitesi Tıp Fakültesi Hastaneleri'nde hastane enfeksiyonları: 2005 yllı sonuçları. TSK Koruyucu Hekimlik Bülteni 2006;5:159-65.

16. Joly-Guillo ML, Vallee E, Bergogne-Berezin E, Philippon A: Distribution of beta-lactamases and phenotype analysis in clinical strains of Acine-tobacter calcoaceticus. J Antimicrob Chemother 1988;22:597-604.

17. Rattanaumpawan P, Lorsutthitham J, Ungprasert P, Angkasekwinai N, Thamlikitkul V. Randomized controlled trial of nebulized colistimethate sodi-ᄀum as adjunctive therapy of ventilator-associated pneumonia caused by Gramnegative bacteria. J Antimicrob Chemother 2010;65:2645-9.

18. Villalon P, Valdezate S, Medina-Pascual MJ, Rubio V, Vindel A, Saez-Nieto JA. Clonal diversity of nosocomial epidemic Acinetobacter baumannii in Spain. J Clin Microbiol 2010 Dec 22 (Epub ahead of print). http://dx.doi. org/10.1128/JCM.01026-10 PMCid:2916618.

19. Kofteridis DP, Alexopoulou C, Valachis A et al Aerosolized plus intravenous colistin versus int $\neg$ ravenous colistin alone for the treatment of ventilator-associated pneumonia: a matched case-control study. Clin Infect Dis 2010;51:1238-44. http://dx.doi.org/10.1086/657242 PMid:20973727.

20. Bogiel T, Kwiecinska-Pirog J, Jachna-Sawicka K, Gospodarek E. Carbapenem-resistant Acinetobac-ter baumannii strains. Med Dosw Mikrobiol 2010;62:119-26.PMid:20873484.

21. Balcı M, Bitirgen $M$, Kandemir B, Türk Arıbaş E, Erayman I. Nozokomiyal Acinetobacter bauman $\neg$ ii suşlarının antibiyotik duyarlıı̆ı. ANKEM Derg 2010;24:28-33.

22. Pankey GA. Tigecycline. J Antimicrob Chemother 2005;56:470-80.

23. Ünlü $M$, Vardar-Ünlü $G$, Yağmuroğlu A: Klinik örneklerden soyutlanan Staphylococcus aureus suşlarına tigesiklin etkinliği. ANKEM Dergisi 2009;23:13-6.

24. Yu YS, Yang Q, Xu XW, Kong HS, Xu GY Zhong BY: Typing and characterization of carbapenem resistant Acinetobacter calcoaceticus-baumannii complex in a Chinese hospital J Med Microbiol 2004;53:653-6.

25. Guriz H, Aysev D, Yavuzdemir Ş. Hastane enfeksiyonlarından etken olarak izole edilen Acinetobacter suşlarının antimikrobiyallere duyarlııkları. Mikrobiyol Bul 1999; 33:289-96. 
26. Ozdemir M, Erayman I, Gundem NS, Baykan M, Baysal B. Hastane enfeksiyonu etkeni Acinetobacter suşlarının çeşitli antibiyotiklere duyarılıklarının araştırıması. ANKEM 2009;23:127-32.

27. Simsek B, Bedir O, Gumral R, Kilic A, Basustaoglu A. Antimicrobial resistance of nosocomial gram-negative bacteria in Gulhane Military Medical Academy Hospital intensive care units. ICAAC. September 12-15, 2010, Boston. http://www.febrilnotropeni.net/newsfiles/29521ICAAC\%202010.doc.

28. Tognim MC, Andrade SS, Silbert S, Gales AC, Jones RN, Sader HS: Resistance trends of Acinetobacter spp. in Latin America and characte $\neg$ rization of international dissemination of multi-drug resistant strains: five-year report of the SENTRY Antimicrobial Surveillance Program. Int J Infect Dis 2004;8:284-91.

29. Maragakis LL, Perl TM. Acinetobacter baumannii: Epidemiology, antimicrobial resistance, and treatment options. Clin Infect Dis 2008;46:1254-63. http://dx.doi.org/10.1086/529198 PMid:18444865.

30. Ruiz J, Núñez ML, Pérez J, Simarro E, Martínez-Campos L, Gómez J. Evoluation of resistance among clinical isolates of Acinetobacter over a 6-year period. Eur J Clin Microbiol Infect Dis 1999;18:292-5. http://dx.doi. org/10.1007/s100960050280 PMid:6756909

31. Çalışkan A. Acinetobacter'lerde direnç ve klonal ilişsinin araştırılması, İnönü Üniversitesi Tıp Fakültesi, Mikrobiyoloji ve Klinik Mikrobiyoloji Anabilim Dalı, Uzmanlık Tezi, Malatya (2008).

32. Çolpan A, Güngör Ş, Baykam N, Dokuzoğuz B. Yoğun bakım ünitelerinden izole edilen Acinetobacter suşlarının antibiyotik direnç durumlarının araştıııması. İnfeksiyon Derg 2002;6:55-8.
33. Güdücüoğlu H, Berktaş M, Bozkurt H, Kurtoğlu MG, Gülmez S. Acinetobacter baumannii suşlarında 1997-2000 ylllarında gözlenen antibiyotik direnci. ANKEM Derg 2002;16:36-9.

34. Hancock REW. Resistance mechanisms in Pseudomonas aeruginosa and other nonfermentative gram-negative bacteria, Clin Infect Dis 1998;27:S939. http://dx.doi.org/10.1086/514909 PMid:9710677.

35. Sarıgüzel FM. Acinetobacter baumannii bakteriye $\neg$ misi: Epidemiyoloji ve kökenlerin antibiyotik duyarlılıkları. Erciyes Üniversitesi Tıp Fakültesi, Mikrobiyoloji ve Klinik Mikrobiyoloji Anabilim Dalı, Uzmanlık Tezi, Kayseri (2008).

36. Yavuz MT, Şahin İ, Behcet M, Öztürk E, Kaya D.Çeşitli klinik örneklerden izole edilen Acineto-bacter baumannii suşlarının antibiyotik duyarlııkları. ANKEM Derg 2006;20:107-10.

37. Zer Y, Akın FEÖ, Namıduru M. Acinetobacter baumannii suşlarında tigesiklin etkinliğinin araştıııması. İnfeksiyon Derg 2007;21:193-6.

38. Kurtoğlu MG, Opuş A ve ark 'Bir Eğitim ve Araştırma Hastanesinde Klinik Örneklerden İzole Edilen Acinetobacter baumannı Suşlarında Antibakteriyel Dirençleri' (2008-2010) Ankem Derg 2011;25:35-41 doi:10.5222 ankem.2011.35.

39. Van Looveren M, Goossens H, ARPAC Steering Group: Antimicrobial resistance of Acinetobacter spp. in Europe. Clin Microbiol Infect 2004;10:684704. 